\title{
Case Report: Pathological Results in Cadavers Suspected to Electrical Injury Referred to the Forensic Medicine Center of Tehran From 2006 to 2016
}

Fares Najari $^{1 *}$, Mohammad Ali Emam Hadi' ${ }^{1}$, Ghazaleh Sadat Araban ${ }^{1}$

1. Department of Forensic Medicine, School of Medicine, Shahid Beheshti University of Medical Sciences, Tehran, Iran.

\begin{tabular}{|c|c|}
\hline $\begin{array}{l}\text { Use vour device toscan } \\
\text { and read the article online }\end{array}$ & Citation: Najari F, Emam Hadi MA, Araban GhS. Pathological Results in Cadavers Suspected to Electrical Injury Referred \\
\hline 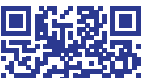 & $\begin{array}{l}\text { to the Forensic Medicine Center of Tehran From } 2006 \text { to 2016. International Journal of Medical Toxicology and Forensic Medi- } \\
\text { cine. 2019; 9(4):261-264. https://doi.org/10.32598/ijmtfm.v9i4.25995 }\end{array}$ \\
\hline $19 \mathrm{~s}$ & doi https://doi.org/10.32598/ijmtfm.v9i4.25995 \\
\hline
\end{tabular}

\section{(i) (3)}

Article info:

Received: 06 Jun 2019

First Revision: 18 Jun 2019

Accepted: 25 Aug 2019

Published: 01 Oct 2019

\section{Keywords:}

Pathology, Forensic medicine, Electrical injury

\begin{abstract}
The electrical injury is a common cause of death needing forensic assessments. In these cases, the histopathological assessment is a routine practice. The aim of this study was to determine the pathological results in cadavers suspected to electrical injury referred to the Forensic Medicine Center of Tehran, Iran. In this observational descriptive-comparative study, 745 consecutive cadavers suspected to electrical injury referred to the Forensic Medicine Center of Tehran from 2006 to 2016 were enrolled; also, the histopathological findings among them were determined and compared according to other variables. The results of this study demonstrated that 44 patients $(86.3 \%)$ of those suspected to have an electrical injury and 101 patients $(92.7 \%)$ of those with definite electrical injury had positive pathological results, showing a statistically significant difference $(\mathrm{P}<0.05)$. The non-routine histopathology assessment is useful and would develop positive results in more than $80 \%$ of the cases.
\end{abstract}

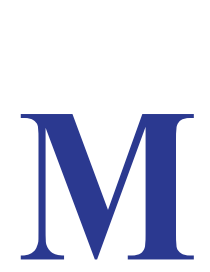

\section{Introduction}

ultiple cases of electrical injuries are reported annually, where the body is integrated into an electrical circuit. The severity and complications of electrical injuries are related to factors such as electrical current, potential differences, current intensity, tissue resistance, the pathway, and passing duration. Intermittent electrical current, the wetness of clothes, and angriness may aggravate the conditions [1-3].
Ventricular fibrillation is the most common ventricular arrhythmia and may be conscious until moments before the collapse. Seizure as a result of direct electrical current from the brain is less frequent. The $100 \mathrm{~mA}$ electrical current passing from the head may result in respiratory arrest and even a shock of more than $5 \mathrm{~A}$ in $60 \mathrm{~Hz} / \mathrm{sec}$ frequency may result in respiratory arrest. The most common entry and exit sites are hands and feet, respectively [4-6].

Contact is not necessary for electrical burn and in a voltage over $300 \mathrm{~V}$, a part of the body may develop a cir-

\footnotetext{
* Corresponding Author:

Fares Najari, MD.

Address: Department of Forensic Medicine, School of Medicine, Shahid Beheshti University of Medical Sciences, Tehran, Iran. Tel: +98 (912) 3195140

E-mail:najar.hospital@sbmu.ac.ir
} 
cuit leading to kissing burning. The aim of this study was to determine the pathological results in cadavers suspected to electrical injury referred to the Forensic Medicine Center of Tehran from 2006 to 2016 [7-9].

In this observational descriptive-comparative study, 745 consecutive cadavers suspected to electrical injury referred to the Forensic Medicine Center of Tehran from 2006 to 2016 were enrolled. The definition of definite and suspected cases was according to records in the medical documents. The inclusion criteria included being suspected of electrical injury and referring to the Forensic Medicine Center of Tehran. Also, the exclusion criteria included the lack of pathology results and legal documents.

The data were extracted from the existing medical documents and recorded in the checklist. The variables were age, sex, location of cadaver finding, voltage, entry and exit site, job, humidity, and pathological findings. The histopathological findings among cadavers were compared according to other variables. The industrial electrical use was considered as high-voltage and the house electrical use was considered as low-voltage. High-risk jobs included electrical manager, plumber, ventilation systems worker, electrical industries employee, elevator worker, and welder. The other occupations were considered as low-risk jobs. Pool, bathroom, toilet, and wellmaker were considered as wet.

The data of 160 subjects were analyzed by SPSS version 13.0 software. The Chi-square test, Analysis of variance, and the independent samples $t$ test were used; also, the P-values of less than 0.05 were considered statistically significant.

The Mean \pm SD age was $30.2 \pm 4.4$ and $30.3 \pm 3.5$ years in the suspected and definite groups $(\mathrm{P}>0.05)$ with the median and mode of 30 and 35 years. There were 3 and 5 female subjects in the suspected and definite groups $(\mathrm{P}>0.05)$. As shown in Table 1 , the location of the cadaver was alike across the groups $(\mathrm{P}>0.05)$. Also, the voltage was the same across the groups and it was higher in male subjects and dry locations, but it was not related to age and entry and exit sites (Figure 1).

The entry and exit sites were the same across the groups $(\mathrm{P}>0.05)$. The age and gender were not related to the entry and exit site $(\mathrm{P}>0.05)$. Also, the humidity was the same across the groups. The results demonstrated that 44 patients $(86.3 \%)$ of those suspected to have an electrical injury and 101 patients $(92.7 \%)$ of those with definite electrical injury had positive pathological results, showing a statistically significant difference $(\mathrm{P}<0.05)$ (Figure 2). Also, the entry and exit site associations were the same in wet and dry locations.

The results demonstrated that the total ratio of electrical injury as the cause of death was $0.81 \% ; 86 \%$ and $92.7 \%$ of the suspected and definite groups had pathological findings without significant difference. Also, the types of pathology results were the same. Epidermal vacuolization, epidermal stretching, and eosinophilic changes were skin findings. The cerebral findings were bleeding and the cardiac findings were nuclear alterations [10].

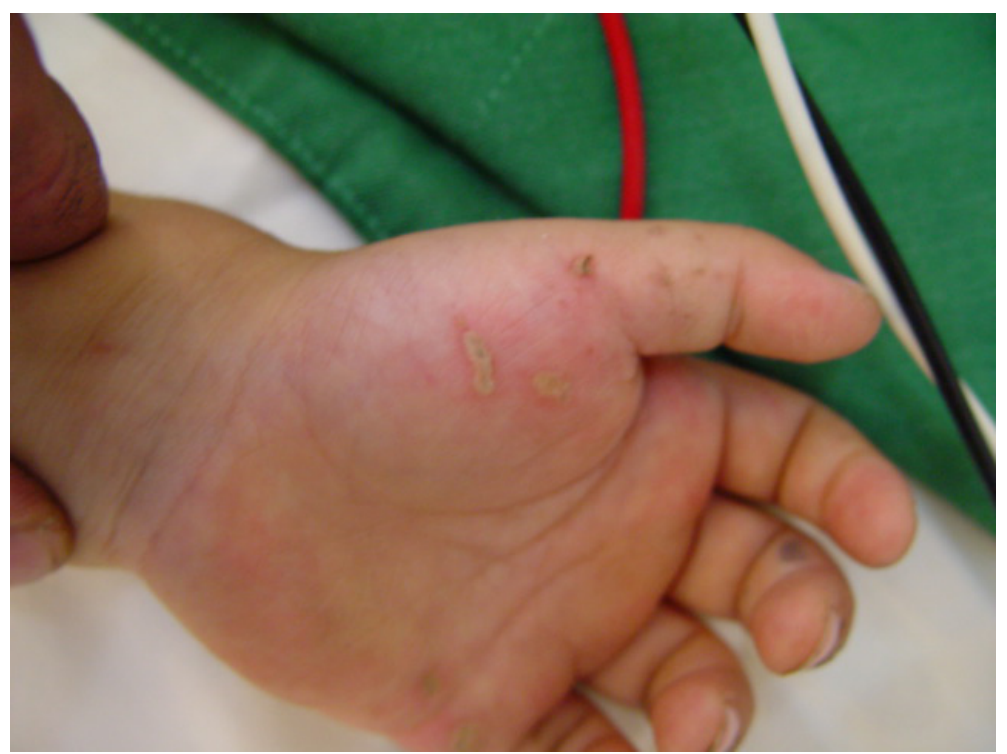

Figure 1. Electrical current entry site 


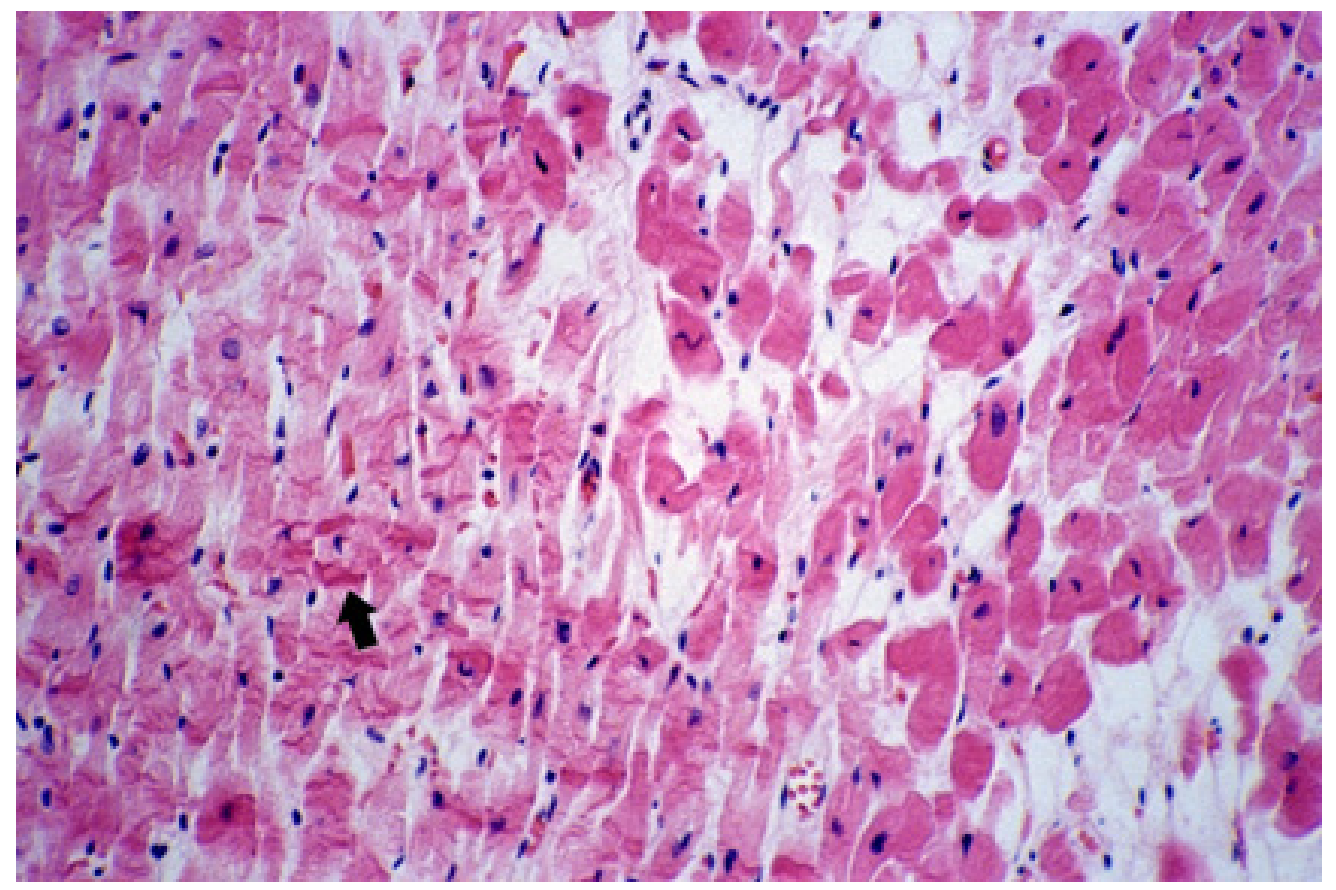

Figure 2. Microscopic view of electrical injury

International Journal of
Medical Toxicology \& forensic Medicine

Schaefer et al. [11] reported that plexopathy and local injuries were the main cerebral findings in our study. In the present study, neuropathology was not done, but the bleeding was similarly a common problem. A cross-sectional study by Aygün et al. [12] among 36 cases showed that injuries were with vacuole formation and release of muscular enzymes, especially creatine phosphokinase; the positive muscular findings may approve the electrical injury. But, it is not in congruence with our study because the muscular alterations were not assessed in the current study and it was because of the lack of muscular sampling in our study. Ramati et al. [13] reported that neuronal injuries and edema and hemorrhage were the most common findings in patients with the electrical injury that demonstrate neuronal injuries and the most important one is edema. But, hemorrhage was the main finding in our study and the edema and neuronal injuries were not determined. Moreover, it may be suggested that only skin in the Extremity and brain samples should be obtained that include $82.6 \%$ of samples with positive pathological findings; also, since only $2.5 \%$ of lung samples were positive, it may be suggested that no lung sample should be obtained.

\section{Conclusion}

Totally, according to the obtained results, it may be concluded that routine histopathology assessment is useful and would develop positive results in more than $80 \%$ of the cases and may help to find the neglected points in cadavers. However, further studies with the larger sample size and multi-center sampling are carried out to attain more definite results, especially about contributing factors for the pathological results in cadavers because of electrical injuries. Also, the exclusion of lung samples and the inclusion of skin, brain, and heart or even solely the skin may result in less confusion besides lower costs in this era.

\section{Ethical Considerations}

\section{Compliance with ethical guidelines}

There was no ethical considerations to be considered in this research.

\section{Funding}

This research did not receive any specific grant from funding agencies in the public, commercial, or not-forprofit sectors.

\section{Author's contributions}

All authors contributed in preparing this article.

\section{Conflict of interest}

The authors have no conflict of interest. 


\section{Acknowledgements}

We should kindly appreciate all kind efforts of personnel of the authopsic Hall.

\section{References}

[1] Koumbourlis AC. Electrical injuries. Critical Care Medicine. 2002; 30(Suppl. 11):S424-30. [DOI:10.1097/00003246200211001-00007] [PMID]

[2] Adukauskiene D, Vizgirdaite V, Mazeikiene S. Electrical injuries. Medicina. 2007; 43(3):259-66. [DOI:10.3390/medicina43030032]

[3] Saukko P, Knight B. Knights forensic pathology. Abingdonon-Thames: Taylor \& Francis; 2004. [DOI:10.1201/b13642]

[4] Bruner JM. Hazards of electrical apparatus. Anesthesiology. 1967; 28(2):396-425. [DOI:10.1097/00000542-196703000-00023] [PMID]

[5] Ferris LP, King BG, Spence PW, Williams HB. Effect of electric shock on the heart. Transactions of the American Institute of Electrical Engineers. 1936; 55(5):498-515. [DOI:10.1109/TAIEE.1936.5057302]

[6] Barry AJ, Fissue. Techniques of crime scene investigation. Boca Raton: CRC Press; 2004.

[7] Wesner ML, Hickie J. Long-term sequelae of electrical injury. Canadian Family Physician. 2013; 59(9):935-9.

[8] Singerman J, Gomez M, Fish JS. Long-term sequelae of lowvoltage electrical injury. Journal of Burn Care \& Research. 2008; 29(5):773-7. [DOI:10.1097/BCR.0b013e318184815d] [PMID]

[9] Fish JS, Theman K, Gomez M. Diagnosis of long-term sequelae after low-voltage electrical injury. Journal of Burn Care \& Research. 2012; 33(2):199-205. [DOI:10.1097/ BCR.0b013e3182331e61] [PMID]

[10] Najari F, Soleimani L, Najari D. Filicide by electrocution. International Journal of Medical Toxicology and Forensic Medicine. 2019; 9(1):39-44. [DOI:10.22037/ijmtfm. v9i1(Winter).22359]

[11] Schaefer NR, Yaxley JP, O'Donohue P, Lisec C, Jeyarajan E. Electrical burn causing a unique pattern of neurological injury. Plastic and Reconstructive Surgery Global Open. 2015 3(4):e378 [DOI:10.1097/GOX.0000000000000344] [PMID] [PMCID]

[12] Aygün D, Gönüllü $H$. The myopathic effects of electrical injury. Ulus Travma Acil Cerrahi Derg. 2010; 16(3):225-8. [PMID]

[13] Ramati A, Pliskin NH, Keedy S, Erwin RJ, Fink JW, Bodnar EN, et al. Alteration in functional brain systems after electrical injury. Journal of Neurotrauma. 2009; 26(10):1815-22. [DOI:10.1089/neu.2008.0867] [PMID] [PMCID] 